\title{
Queer Theory in Flux: Views from Past to Present
}

\section{Lois-Anne Watt}

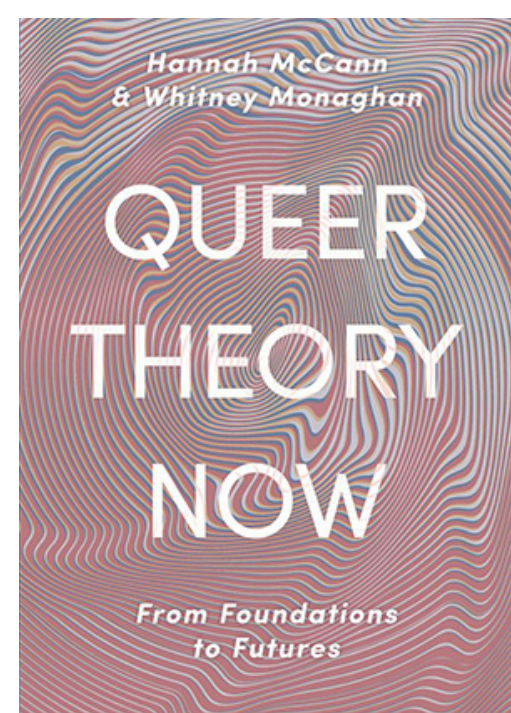

McCann, Hannah and Monaghan, Whitney. 2019. Queer Theory Now: From Foundations to Futures. London: Bloomsbury Publishing

Queer Theory Now: From Foundations to Futures by Hannah McCann and Whitney Monaghan (2019) is an exciting new textbook aiming to introduce and unpack the intricacies of queer theory to new (and seasoned) readers. Throughout the book, the authors outline a detailed discussion of queer theory's origins, transformations and contentions within several key debates which have helped shape its response to multiple controversial political discussions regarding the ways in which we can understand gender and sexuality.

The authors open their discussion by, effectively, holding the readers hand and guiding us through the minefield that emerges when approaching the term, "queer". Indeed, immediately within the first chapter, McCann and Monaghan highlight the distinction between queer as theory and queer as identity. In doing so, they distinguish how this book is an attempt to place this distinction and tension within a chronological order. Yet, despite this, the authors are fast to remark on how both queer identity and theory have worked to reaffirm, as well as contest, each other. And so, the textbook draws upon this relationship through its emergence within the blurred lines that distinguish academics, activism and art. In Queer Theory Now, the authors select some of the key arguments that have taken (and are taking place) within queer theory and how such arguments have worked towards its ongoing reinvention. As such, the authors seek to complicate any simplistic and linear interpretations of queer theory by invoking its many debates in relation to other epistemologies, such as poststructuralism, postmodernism, feminism and critical race studies.

Structurally, this book can be roughly divided into three sub-sections: chapters one to four approach the origins of queerness as an academic lens and discuss some of the early scholarly contributions, primarily from Michel Foucault. As well as charting the beginnings of the Homophile, Gay Liberation and LGBT+ movements in the West, the authors also discuss the growing prevalence of feminist theory and feminism in the second half of the 20th century.

The reader is presented first with an overview of Foucault's framing of sexuality as something routed within a complex power dynamism that is reinforced through specific discourses. In covering the bases of Foucault's 
critique of the repressive hypothesis, the authors help to frame the constructive aspect of gender and sexuality for the reader whilst leaving some questions open in presenting some of of the critiques made against his argument. This includes a discussion of the absence of women in Foucault's analysis of power and sexuality, and a later reworking of his theory to include ethnic minorities.

This discussion pairs excellently with the authors following analysis of the initial homophile movement in the US and its subsequent splintering into the Gay Liberation movement. However, in chapter three, McCann and Monaghan further complicate this history by presenting an overview of feminism, and specifically, its relationship to sexuality and the homophile/ Gay Liberation movements. In opening this chapter, the authors consider what the relationship between feminist and queer theory is by asking whether we should think of queer theory as connected to feminism, or not. After going through the basics of feminist history - covering the core concepts related to feminisms waves alongside the ideological splits between different feminist approaches and the subsequent tensions which emerged from these splits - the reader is left with a wide overview that transitions nicely into a discussion of feminism's dangers, which include the grand narratives associated with feminism and its oftentimes universalising ideals.

The authors expand upon these complex internal tensions within feminism through a detailed discussion of the so-called Sex Wars. Crucial to this analysis is the way in which the authors use this point to bring to the forefront the tendency for feminist (and queer) theory to function within universalist, Western ontological assumptions that are problematically applied to global contexts. The authors here elaborate upon this through the example of the subject/object dualism which often manifests into other specifically, Western dichotomies (nature/culture and the mind/body are two of the most prominent). As such, this chapter outlines how queer theory is not only connected to feminism but how early queer theorists helped shift the trajectories of feminist debate and discussion as well as critiquing the apparent maleness of sexuality studies, and subsequently the gender-binary focus of feminism.

The second section (chapters four to six) goes on to address the emergence of queer theory beyond post-structuralism/modernism and feminist theory. Chapter four takes the reader into this development through a historic discussion of the AIDS/HIV epidemic (with a focus on the USA, Australia, and the UK) and the activism associated with it during the 1980s and 1990s. This is an excellent chapter for those looking for an overview on this, as McCann and Monaghan take the space to really evaluate the differences between the activism and the varied responses which governments took (or failed to take) in response to the emergence of HIV and AIDS. In doing so, McCann and Monaghan explore the role that HIV/AIDS and its activists had in influencing the core ideas of queer theory, which emerged soon after. With that said, the authors also refer to prior writings about Foucault when exploring how then activists and academics attacked the intense power dynamics involved in the deeply political nature of HIV/AIDS and its construction within the political, medical, and social discourses of the time.

In continuing from this strain, in chapter five, the authors introduce an excellent discussion of those keystone theorists who did the work to establish some of queer theory's central premises. The authors set this chapter to an overview of Butler and Sedgwick's work, and they succeed in outlining the core ideas of both scholars in a way that is approachable to many readers, taking apart some of the complexities of Butler's writing, in particular, whilst elaborating on the crucial divergences of both scholars' approaches to understanding gender and sexuality. What impressed me, 
however, was again the way in which the authors took the time in their analysis of Butler to point to a central critique of their work which again comes back to the friction of queer theory's origins within a Western ontology that places significance on the mind/body or subject/object dualism. Whilst the authors acknowledge how Butler pointed out the prevalence of such binary modes of thought and their problematic nature, a critique of Butler is pulled from the work of Marie-Paule Ha who referenced how particular epistemologies and conceptions of gender and sexuality cannot be universalised into a global context, as in many contexts the conceptualisation of mind and body is radically different (McCann and Monaghan, 2019:124).

The discussion of cultural plurality in understandings of gender and sexuality is a crucial point, and the authors reflexively return to issues of representation within queer theory in addressing the constant reemergence and complication of issues related to racism and non-Western forms of knowledge. Furthermore, in chapter six, a concern with the body is taken up in the authors discussion of the emergence of identity politics during the 1990s and the growing prominence of transgender issues. The authors reflect how this has worked to further shape queer theory. This acknowledgement works well when moving into the concluding chapters (seven to eight) of the book that shifts into a discussion about how queer theory exists in relation to our present moment and how the past can present difficulties in negotiating a contemporary space for queer theory.

In chapter seven, greater consideration is given to the often marginalised discussion of intersectional analysis within queer theory, once more linking back to chapter three's discussion of the different ideologies within feminism and the emergence of intersectionality as a particular lens used to approach the complex interplay of exploitation experienced along lines of race, ethnicity, sexuality, and so on. In moving from there, the final chapter works to address what the future of queer theory may be, in acknowledging its journey outlined in the past chapters, as well as why it proves to be an important tool in unravelling the issues dealt with throughout the book.

With that all said, Queer Theory Now proves to be a book which can be incredibly useful both for a reader who is looking to get to grips with the core aspects of the theory as well as for seasoned academics and writers who are looking to once more familiarise themselves with some of the essential theory and history associated with it. McCann and Monaghan also do well to provide some useful references for further reading and watching; providing at the end of each chapter some scholarly and film recommendations to help the reader get a better grasp of what are, sometimes, very quick overviews. What makes this book stand out, in this current time, however, is its constant reflexivity regarding the intersectional aspects of queer theory that overlap with feminist theory, indigenous studies and critical race studies. This both helps to critique and pull queer theory away from its origins in primarily Western ontologies, helping to position the reader in such a way to see that queer theory is not, necessarily, progressing forward in time from past debates into new ones, but rather, is constantly influenced by its past in such a way that brings new tensions and questions into light. Whilst this may often seem incredibly complicated and existential for those trying to make sense of it all, McCann and Monaghan have presented us with a book that makes it all seem a little bit clearer. 